\title{
Recurrent Hypoglycemia Increases Anxiety and Amygdala Norepinephrine Release During Subsequent Hypoglycemia
}

\author{
Ewan McNay* \\ Behavioral Neuroscience, University at Albany (SUNY), Albany, NY, USA
}

Recurrent hypoglycemia $(\mathrm{RH})$ is a common and debilitating side effect of therapy in patients with both type 1 and, increasingly, type 2 diabetes. Previous studies in rats have shown marked effects of $\mathrm{RH}$ on subsequent hippocampal behavioral, metabolic, and synaptic processes. In addition to impaired memory, patients experiencing $\mathrm{RH}$ report alterations in cognitive processes that include mood and anxiety, suggesting that $\mathrm{RH}$ may also affect amygdala function. We tested the impact of $\mathrm{RH}$ on amygdala function using an elevated plus-maze test of anxiety together with in vivo amygdala microdialysis for norepinephrine (NEp), a widely used marker of basolateral amygdala cognitive processes. In contrast to findings in the hippocampus and prefrontal cortex, neither RH nor

OPEN ACCESS

Edited by: Subbiah Pugazhenthi, Denver VA Medical Center, USA

Reviewed by:

Craig Beall, University of Exeter, UK Sampath Rangasamy, TGen, USA

${ }^{*}$ Correspondence:

Ewan McNay emcnay@albany.edu

Specialty section:

This article was submitted to

Diabetes, a section of the journal Frontiers in Endocrinology

Received: 14 August 2015 Accepted: 02 November 2015 Published: 20 November 2015

Citation:

McNay E (2015) Recurrent Hypoglycemia Increases Anxiety and Amygdala Norepinephrine Release During Subsequent Hypoglycemia. Front. Endocrinol. 6:175. doi: 10.3389/fendo.2015.00175 acute hypoglycemia alone significantly affected plus-maze performance or NEp release. However, animals tested when hypoglycemic who had previously experienced $\mathrm{RH}$ had elevated amygdala NEp during plus-maze testing, accompanied by increased anxiety (i.e., less time spent in the open arms of the plus-maze). The results show that $\mathrm{RH}$ has widespread effects on subsequent brain function, which vary by neural system.

Keywords: hypoglycemia, insulin, amygdala, anxiety, diabetes, norepinephrine, recurrent hypoglycemia

\section{INTRODUCTION}

The opening paragraph of a recent commentary (1) describes the significance of recurrent hypoglycemia (RH) vividly: " $[\mathrm{RH}]$ is the limiting factor in the glycemic management of diabetes. It causes recurrent morbidity in most people with type 1 diabetes and many with advanced type 2 diabetes and is sometimes fatal. It impairs defenses against subsequent hypoglycemia and, thus, causes a vicious cycle of recurrent hypoglycemia. The barrier of hypoglycemia generally precludes maintenance of euglycemia over a lifetime of diabetes."

Hypoglycemia is a common side effect of insulin therapy in both type 1 and type 2 diabetes mellitus (T1 and T2DM). RH, and specifically the impact of RH on the brain (both in actuality and in patients' worry about such impact), is the biggest obstacle to optimal, intensive insulin therapy aimed at tightly preventing hyperglycemia and restoring normal blood glucose (2-4). The majority of work studying RH and the brain has been in the context of RH-induced hypoglycemiaassociated autonomic failure (HAAF): unawareness of and inability to respond to hypoglycemia that can in extremes lead to coma and death, focusing on detection of glucose levels in the ventromedial hypothalamus $(\mathrm{VMH})(5-8)$. However, $\mathrm{RH}$ is also clinically associated with marked cognitive and behavioral impairments such as mood swings, impaired judgment and mental flexibility, 
memory loss, and debilitating anxiety (9-17), many of which are likely to be associated with alterations in amygdala function. Cognitive impairment is especially prevalent during subsequent hypoglycemia, which can have profound consequences: for instance, car accidents are a leading cause of death among diabetic patients, linked to impaired judgment during hypoglycemia $(10-13,18)$.

Despite this, the neural and cognitive impact of $\mathrm{RH}$ has been relatively little studied outside the VMH. Our recent review (19) concluded that there is strong evidence that $\mathrm{RH}$ can alter cognitive and neural function, but studies of RH in human beings have often had difficulty in controlling for confounding disease states and/or variable prior history of hypoglycemia $(6,15,17,20,21)$. In three previous reports that examined $\mathrm{RH}$ in rats, we have characterized the impact of $\mathrm{RH}$ on subsequent hippocampal function including spatial memory $(22,23)$ and on mental flexibility, mediated by the prefrontal cortex (24). The rat model of $\mathrm{RH}$ used in those studies accurately simulates the effects of RH and HAAF in human beings (22-28), and we have continued to use this model in the present work. Here, we examined the impact of RH on amygdala function. The amygdala plays a key role in anxiety and mood, which are reported to be dysregulated after $\mathrm{RH}$ in human beings, and previous studies have shown that similarly to the hippocampus, cognitive processing in the amygdala is limited by glucose metabolism $(29,30)$, suggesting that RH may alter subsequent amygdala function.

A key finding from the studies of $\mathrm{RH}$ and hippocampal function is that the impact of $\mathrm{RH}$ varies with acute glycemic state: although hippocampal function is preserved and perhaps enhanced when tested at euglycemia, marked impairment is seen during a subsequent hypoglycemic episode $(22,23)$, matching symptoms seen in humans. In contrast, mental flexibility and PFC glucose metabolism were impaired after $\mathrm{RH}$ even when measured at euglycemia, suggesting that the impact of $\mathrm{RH}$ may vary by brain region. That hypothesis is supported by the findings reported here: we show using an elevated plus-maze task that after $\mathrm{RH}$, rats show no change in anxiety or amygdala norepinephrine (NEp) release when measured at euglycemia, but are significantly more anxious during subsequent hypoglycemia, accompanied by elevated amygdala NEp release. NEp release in the basolateral amygdala (BLA) has been widely shown to be a marker for amygdala cognitive modulation (31-33).

\section{MATERIALS AND METHODS}

\section{Experimental Timeline}

All procedures were approved by the Institutional Animal Care and Use Committee at the University at Albany. 36 male SpragueDawley rats (Charles River, Wilmington, MA, USA) were pair housed in enriched conditions (toys, plastic tubing, paper cups, etc.) From 11 weeks of age, rats are handled daily for a minimum of $10 \mathrm{~min}$; this reduces stress hormone release at the time of testing to baseline levels (22). At 13-14 weeks, animals underwent stereotactic implantation of a microdialysis guide cannula (CMA12, CMA/Microdialysis) into the left BLA, then 1 week of singlehoused recovery with close monitoring and continued handling. At $14-15$ weeks, animals were treated with either i.p. insulin or i.p. saline once daily for 3 days, then tested on the fourth day, humanely killed, and samples taken for analysis. At the start of treatment, animals were randomly assigned to either control or $\mathrm{RH}$ conditions; on the day of testing, animals were randomly assigned to either hypoglycemic or euglycemic conditions. This created four groups with between 8 and 10 animals in each group in a $2 \times 2$ factorial design.

\section{Surgical Procedures}

Rats were anesthetized with 5\% isoflurane. Standard sterile stereotaxic surgical procedures were used as described previously (3436) to implant the microdialysis guide cannula, secured in place with acrylic cement and two screws, and a dummy stylet was inserted. Rats recovered in a heated chamber and returned to their home cages once they had regained consciousness and full motor control. Animal recovery was monitored for 3 days. Rimadyl once daily was used for post-surgical analgesia. Correct cannula placement was confirmed visually in all animals at the time of tissue extraction by locating the tract path created by the cannula which terminated in the BLA: all animals had correctly placed cannulae.

\section{Microdialysis}

As published $(22,30,37-40)$ : a fresh probe was inserted, and animals were acclimated for $2 \mathrm{~h}$ prior to testing. The dialysis membrane was $1 \mathrm{~mm}$. Rats moved freely, avoiding any confound from restraint stress. Probes were perfused with an artificial extracellular fluid [aECF; composition in millimolar: $153.5 \mathrm{Na}$, $4.3 \mathrm{~K}, 0.41 \mathrm{Mg}, 0.71 \mathrm{Ca}, 139.4 \mathrm{Cl}, 1.25$ glucose, buffered at $\mathrm{pH} 7.4$ (40)] at $1.5 \mu \mathrm{L} / \mathrm{min}$. Microdialysis samples were frozen for later NEp analysis.

\section{Hypoglycemia}

Hypoglycemia was induced with $10 \mathrm{U} / \mathrm{kg}$ insulin (Humulin, Eli Lilly) given i.p. to animals made hypoglycemic for the first time, or either 8 or $6 \mathrm{U} / \mathrm{kg}$ (because of reduced counter-regulation) to $\mathrm{RH}$ animals $(22,23,41)$; control animals receive volume-matched sterile saline.

\section{RH Model}

The model used here ( $3 \mathrm{~h}$ of moderate hypoglycemia on each of three consecutive days, followed by testing on the fourth day) has been validated as accurately recreating adaptation seen in human patients with RH. Animals received i.p. insulin (Humulin, Eli Lilly) at 10,8 , and $6 \mathrm{U} / \mathrm{kg}$ over the 3 days, with reduction in doses compensating for reduced counterregulation due to HAAF. This reliably produced $2-3 \mathrm{~h}$ between 40 and $50 \mathrm{mg} / \mathrm{dL}$ plasma glucose; any animal not spontaneously recovering after $3 \mathrm{~h}$ was returned to normoglycemia using i.p. glucose. Results from this model closely track those obtained in a 16-month study using once-weekly 3-h hypoglycemia (23), matching the experience of human patients receiving insulin therapy (42-45). In our previous studies, data from T1DM and non-diabetic animals did not differ (22), supporting RH studies in non-diabetic animals to avoid confound from disease-state variables; these data were consistent not only for behavior but also for hippocampal metabolism (22) and synaptic electrophysiology (23). During hypoglycemia, animals were randomly sampled via thigh prick to confirm target hypoglycemia. 


\section{Performance Variable Controls}

In studies to date, RH in our model has not impaired or reduced motor activity, visual acuity, or, e.g., motivation: for example, $\mathrm{RH}$ animals make the same number of maze-arm choices $(22,23)$, have the same latency to seek reward (24), and perceive both visual and textural stimuli as well as or better than control animals (24). We confirmed that RH had no measureable effects on motor performance, motivation, or sensory acuity using small separate cohorts of animals, treated identically to those reported here and tested on a simple Y-maze alternation task.

\section{Elevated Plus-Maze Testing}

With microdialysis throughout, animals were placed into the center of a four-arm plus-maze constructed from opaque black plexiglas and allowed to explore freely for $10 \mathrm{~min}$, then returned to home cages. Two, opposing, arms of the four-arm maze had no walls; the other two arms had $20 \mathrm{~cm}$-high walls. Animals spend the majority of time in a closed arm with periodic forays to explore the open arms and/or cross the maze center. Increased time spent in the open arms is taken as a measure of decreased anxiety. Microdialysis is performed in the BLA, where this task is mediated (46-49).

\section{Sample Analysis}

Microdialysis samples were measured for NEp using HPLC on an ESA Coulochem III.

\section{Data Analysis}

Data were analyzed in GraphPad Prism using a two-way ANOVA design with RH (or control) and acute glycemic state as the two factors. Where significant main effects were seen, post hoc group comparisons using Tukey's multiple comparisons test identified specific inter-group differences.

\section{RESULTS}

\section{Plus-Maze Performance}

Both RH treatment and acute glycemic state had significant effects on anxiety, as measured by time spent in the open arms during plus-maze testing (both $p<0.001$ ). As shown in Figure 1, post hoc comparisons showed that animals in the RH-hypo group spent significantly less time in the open arms than animals in all other groups, indicating increased anxiety (all $p<0.001$ ). No other inter-group comparisons showed significant differences. Importantly, no effect of RH was seen on number of center-crossings, supporting the conclusion from our performance control experiments that this difference in open-arm time was not the result of altered motor function or motivation in the RH-hypo group.

\section{Amygdala Norepinephrine Release}

Mean microdialysis sample NEp concentration during the plusmaze testing is shown in Figure 2, reported as a percentage of baseline NEp concentration (with baseline defined as the mean of the three samples immediately prior to placement on the plus-maze; absolute baseline NEp levels did not vary across groups). Consistent with the behavioral data, significant effects
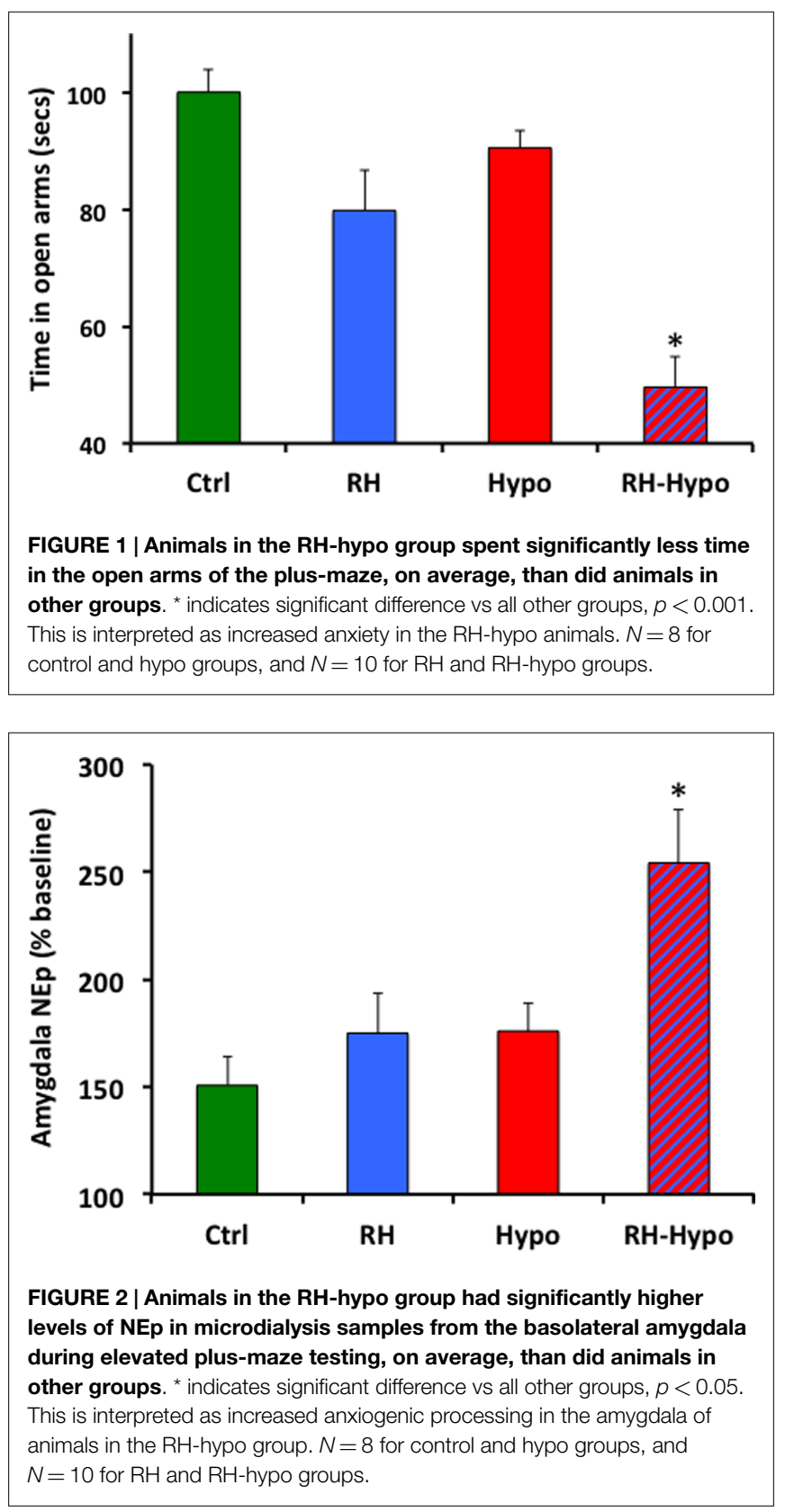

of both treatment and glycemic state were seen (both $p<0.05$ ) in which post hoc comparisons revealed to be due to a significantly increased NEp concentration in samples from RH-hypo animals compared to those in all other groups (all $p<0.05$, no other significant inter-group differences).

\section{DISCUSSION}

Our data are both consistent with, and extend, previous studies that have examined the impact of $\mathrm{RH}$ on subsequent cognitive and neural function: when tested during a hypoglycemic episode, animals with prior RH treatment showed both heightened anxiety and increased amygdala activity, assessed by NEp levels in the BLA. 
Our previous work $(22-24,50)$ suggested that neural adaptations seen following $\mathrm{RH}$ might be maladaptive during subsequent hypoglycemia. This is consistent with the clinical experience of patients, where $\mathrm{RH}$ is associated with, e.g., increased risk of death while driving. Patients also report symptoms, including alterations in mood and anxiety, that are suggestive of altered emotional processing subsequent to $\mathrm{RH}$ : the present data support these reports and suggest that amygdala responsiveness to an aversive stimulus such as exposure on an elevated, open platform may be increased when hypoglycemic after RH. Because amygdala cognitive processing causes increased local glucose metabolism (29), meeting the metabolic requirements of such increased amygdala activation might further diminish the brain's ability to function optimally at times of reduced glucose availability.

On the other hand, it is possible to speculate (based on the small amount of data presented here) that increased anxiety, fear, or similar emotional arousal might be at least somewhat adaptive in that it could serve as a signal for danger at times of hypoglycemia, alerting the patient to an acute need for fuel. One common effect of $\mathrm{RH}$ is diminished release of stress hormones during hypoglycemia [known as HAAF; $(5,51,52)$ ]: increased amygdala responsiveness caused by RH could, perhaps, be a beneficial adaptation that would oppose and attenuate reduced awareness of hypoglycemia. Stress hormones including epinephrine and glucocorticoids are key modulators of cognitive function, and especially of improved performance at times of moderate stress $(31,53-55)$, effects that are transduced via the amygdala; it is hence possible that an increase in amygdala responsiveness may be adaptive in acting to positively modulate other brain regions [in particular, the hippocampus; (55-57)] even when systemic hormone release is attenuated. Importantly, though, one study that examined amygdala metabolism in humans, during hypoglycemia, found that in contrast to the present findings fluorodeoxyglucose uptake was better maintained in the amygdala of aware vs unaware patients (58); this is in contrast to our data that suggest increased amygdala activity in the RH animals which would be expected to correspond to hypoglycemia-unaware patients. Although there are significant methodological differences as well as a species difference between the studies, this finding does constrain the ability to generalize from the small dataset presented here. It is also true that stressrelated hormones, particularly epinephrine, are released when

\section{REFERENCES}

1. Cryer PE. Severe hypoglycemia predicts mortality in diabetes. Diabetes Care (2012) 35:1814-6. doi:10.2337/dc12-0749

2. Amiel S. Cognitive function testing in studies of acute hypoglycaemia: rights and wrongs? Diabetologia (1998) 41:713-9. doi:10.1007/s001250050973

3. Cooper MN, O'Connell SM, Davis EA, Jones TW. A population-based study of risk factors for severe hypoglycaemia in a contemporary cohort of childhoodonset type 1 diabetes. Diabetologia (2013) 56:2164-70. doi:10.1007/s00125013-2982-1

4. Pettitt DJ, Talton J, Dabelea D, Divers J, Imperatore G, Lawrence JM, et al. Group, Prevalence of diabetes in U.S. youth in 2009: the SEARCH for diabetes in youth study. Diabetes Care (2014) 37:402-8. doi:10.2337/dc13-1838

5. Cryer PE. Hypoglycaemia-associated autonomic failure. In: Frier BM, Fisher BM, editors. Hypoglycaemia and Diabetes: Clinical and Physiological Aspects. London: Edward Arnold (1993). p. 275-83.

6. Dagogo-Jack SE, Cryer PE. Hypoglycemia-associated autonomic failure in insulin-dependent diabetes mellitus: recent antecedent hypoglycemia reduces hypoglycemic but such release diminishes after RH: thus, the enhanced anxiety in the RH-hypo group observed here is somewhat paradoxical and the amygdala's response to stress hormones under such conditions may repay further study.

The role of hypoglycemia-associated hormone release in alteration of cognitive processes subsequent to $\mathrm{RH}$ merits further attention. One of the best supported molecular causes of HAAF, in the $\mathrm{VMH}$, is hypoglycemia-associated GC release, and several studies show that prevention of GC signaling in the $\mathrm{VMH}$ during RH prevents HAAF $(7,59-61)$. Similar causality may be involved in the cognitive impact of $\mathrm{RH}$ : glucocorticoid receptors (GRs) are expressed at high levels in the hippocampus $(62,63)$, and GCs have been extensively shown to mediate hippocampal damage from metabolic stressors (such as hypoglycemia): specifically, GCs exacerbate damage from inadequate glucose supply (64-66) and are linked to excitotoxic cell death following severe hypoglycemia. Conversely, when fuel supply is adequate, GCs enhance hippocampal memory and glutamate release (54, 55, 67): this pattern closely matches the impact of RH on hippocampal function seen in our previous work $(22,23)$. We did not measure GC levels either systemically or centrally during these studies, but future work should consider including such measurements.

Taken together with our previous studies, the findings here indicate that $\mathrm{RH}$ affects multiple neural systems and brain structures, with the impact of RH varying by region and system. For instance, during subsequent euglycemia, RH enhances hippocampal memory $(22,23)$, impairs mental flexibility processes in the prefrontal cortex (24), but does not affect performance in an elevated plus-maze test of anxiety (present data). The ability of a rodent model of RH to accurately mimic many of the cognitive effects seen in human patients after RH suggests that this is an appropriate system for further studies aimed at identifying the molecular mechanisms transducing the cognitive, neural, and metabolic impact of $\mathrm{RH}$, with a goal of identifying appropriate therapeutic approaches to prevention and intervention.

\section{FUNDING}

This work was supported by funding from the American Diabetes Association (Award 7-12-BS-126).

autonomic responses to, symptoms of, and defense against subsequent hypoglycemia. J Clin Invest (1993) 91:821-8. doi:10.1172/JCI116302

7. Diedrich L, Sandoval D, Davis S. Hypoglycemia associated autonomic failure. Clin Auton Res (2002) 12:358-65. doi:10.1007/s10286-002-0035-9

8. Cryer PE. Diverse causes of hypoglycemia-associated autonomic failure in diabetes. N Engl J Med (2004) 350:2272-9. doi:10.1056/NEJMra031354

9. Strachan MW, Deary IJ, Ewing FM, Frier BM. Recovery of cognitive function and mood after severe hypoglycemia in adults with insulin-treated diabetes. Diabetes Care (2000) 23:305-12. doi:10.2337/diacare.23.3.305

10. Clarke WL, Cox DJ, Gonder-Frederick LA, Kovatchev B. Hypoglycemia and the decision to drive a motor vehicle by persons with diabetes. JAMA (1999) 282:750-4. doi:10.1001/jama.282.8.750

11. Cox D, Gonder-Frederick L, Kovatchev B, Clarke W. The metabolic demands of driving for drivers with type 1 diabetes mellitus. Diabetes Metab Res Rev (2002) 18:381-5. doi:10.1002/dmrr.306

12. Cox DJ, Gonder-Frederick LA, Kovatchev BP, Julian DM, Clarke WL. Progressive hypoglycemia's impact on driving simulation performance. Occurrence, awareness and correction. Diabetes Care (2000) 23:163-70. 
13. Stork AD, van Haeften TW, Veneman TF. The decision not to drive during hypoglycemia in patients with type 1 and type 2 diabetes according to hypoglycemia awareness. Diabetes Care (2007) 30:2822-6. doi:10.2337/dc06-1544

14. Brands AM, Biessels GJ, de Haan EH, Kappelle LJ, Kessels RP. The effects of type 1 diabetes on cognitive performance: a meta-analysis. Diabetes Care (2005) 28:726-35. doi:10.2337/diacare.28.3.726

15. Fruehwald-Schultes B, Born J, Kern W, Peters A, Fehm H. Adaptation of cognitive function to hypoglycemia in healthy men. Diabetes Care (2000) 23:1059-66. doi:10.2337/diacare.23.8.1059

16. Hannonen R, Tupola S, Ahonen T, Riikonen R. Neurocognitive functioning in children with type-1 diabetes with and without episodes of severe hypoglycaemia. Dev Med Child Neurol (2003) 45:262-8. doi:10.1017/ S0012162203000501

17. Hershey T, Craft S, Bhargava N, White NH. Memory and insulin dependent diabetes mellitus (IDDM): effects of childhood onset and severe hypoglycemia. J Int Neuropsychol Assoc (1997) 3:509-20.

18. Cox D, Penberthy J, Zrebiec J, Weinger K, Aikens J, Stetson B, et al. Diabetes and driving mishaps: frequency and correlations from a multinational survey. Diabetes Care (2003) 26:2329-34. doi:10.2337/diacare.26.8.2329

19. McNay E, Cotero V. Mini-review: impact of recurrent hypoglycemia on cognitive and brain function. Physiol Behav (2010) 100:234-8. doi:10.1016/j.physbeh. 2010.01.004

20. Hvidberg A, Fanelli C, Hershey T, Terkamp C, Craft S, Cryer P. Impact of recent antecedent hypoglycemia on hypoglycemic cognitive dysfunction in non-diabetic humans. Diabetes (1996) 45:1030-6. doi:10.2337/diabetes.45.8. 1030

21. Amiel S, Pottinger R, Archibald H, Chusney G, Cunnah D, Prior P, et al. Effect of antecedent glucose control on cerebral function during hypoglycemia. Diabetes Care (1991) 14:109-18. doi:10.2337/diacare.14.2.109

22. McNay EC, Sherwin RS. Effect of recurrent hypoglycemia on spatial cognition and cognitive metabolism in normal and diabetic rats. Diabetes (2004) 53:418-25. doi:10.2337/diabetes.53.2.418

23. McNay EC, Williamson A, McCrimmon RJ, Sherwin RS. Cognitive and neural hippocampal effects of long-term moderate recurrent hypoglycemia. Diabetes (2006) 55:1088-95. doi:10.2337/diabetes.55.04.06.db05-1314

24. Jahagirdar V, Ramcharitar J, Cotero VE, McNay EC. Moderate recurrent hypoglycemia markedly impairs set-shifting ability in a rodent model: cognitive and neurochemical effects. Open Diabetes J (2012) 5:1-7. doi:10.2174/ 1876524601205010001

25. Maran A, Lomas J, Macdonald I, Amiel S. Lack of preservation of higher brain function during hypoglycemia in patients with intensively-treated IDDM. Diabetologia (1995) 38:1412-8. doi:10.1007/BF00400601

26. Jones T, Borg W, Borg M, Boulware S, McCarthy G, Silver D, et al. Resistance to neuroglycopenia; an adaptive response during intensive insulin treatment of diabetes. J Endocrinol Metab (1997) 82:1713-8. doi:10.1210/jcem. 82.6.3993

27. Lobmann R, Smid HG, Pottag G, Wagner K, Heinze H-J, Lehnert H. Impairment and recovery of elementary cognitive function induced by hypoglycemia in type-I diabetic patients and healthy controls. J Clin Endocrinol Metab (2000) 85:2758-66. doi:10.1210/jcem.85.8.6737

28. Jacob RJ, Dziura J, Blumberg M, Morgen JP, Sherwin RS. Effects of recurrent hypoglycemia on brainstem function in diabetic BB rats: protective adaptation during acute hypoglycemia. Diabetes (1999) 48:141-5. doi:10.2337/diabetes.48. 1.141

29. Sandusky LA, Flint RW, McNay EC. Elevated glucose metabolism in the amygdala during an inhibitory avoidance task. Behav Brain Res (2013) 245:83-7. doi:10.1016/j.bbr.2013.02.006

30. McNay EC, Fries TM, Gold PE. Decreases in rat extracellular hippocampal glucose concentration associated with cognitive demand during a spatial task. Proc Natl Acad Sci U S A (2000) 97:2881-5. doi:10.1073/pnas.050583697

31. Ferry B, Roozendaal B, McGaugh JL. Role of norepinephrine in mediating stress hormone regulation of long-term memory storage: a critical involvement of the amygdala. Biol Psychiatry (1999) 46:1140-52. doi:10.1016/S0006-3223(99) 00157-2

32. McIntyre CK, Hatfield T, McGaugh JL. Amygdala norepinephrine levels after training predict inhibitory avoidance retention performance in rats. Eur $J$ Neurosci (2002) 16:1223-6. doi:10.1046/j.1460-9568.2002.02188.x

33. McReynolds JR, Donowho K, Abdi A, McGaugh JL, Roozendaal B, McIntyre CK. Memory-enhancing corticosterone treatment increases amygdala norepinephrine and Arc protein expression in hippocampal synaptic fractions. Neurobiol Learn Mem (2010) 93:312-21. doi:10.1016/j.nlm.2009.11.005

34. McNay EC, Ong CT, McCrimmon RJ, Cresswell J, Bogan JS, Sherwin RS. Hippocampal memory processes are modulated by insulin and high-fat-induced insulin resistance. Neurobiol Learn Mem (2010) 93:546-53. doi:10.1016/j.nlm. 2010.02.002

35. Pearson-Leary J, McNay EC. Intrahippocampal administration of amyloidbeta(1-42) oligomers acutely impairs spatial working memory, insulin signaling, and hippocampal metabolism. J Alzheimers Dis (2012) 30:413-22.

36. McNay EC, Sandusky LA, Pearson-Leary J. Hippocampal insulin microinjection and in vivo microdialysis during spatial memory testing. J Vis Exp (2013) 71:e4451. doi:10.3791/4451

37. McNay E, Gold P. Extracellular glucose concentrations in the rat hippocampus measured by zero-net-flux: effects of microdialysis flow rate, strain, and age. $J$ Neurochem (1999) 72:785-90. doi:10.1046/j.1471-4159.1999.720785.x

38. McNay EC, Gold PE. Age-related differences in hippocampal extracellular fluid glucose concentration during behavioral testing and following systemic glucose administration. J Gerontol A Biol Sci Med Sci (2001) 56:B66-71. doi:10.1093/ gerona/56.2.B66

39. McNay EC, McCarty RC, Gold PE. Fluctuations in brain glucose concentration during behavioral testing: dissociations between brain areas and between brain and blood. Neurobiol Learn Mem (2001) 75:325-37. doi:10.1006/nlme.2000. 3976

40. McNay EC, Sherwin RS. From artificial cerebro-spinal fluid (aCSF) to artificial extracellular fluid (aECF): microdialysis perfusate composition effects on in vivo brain ECF glucose measurements. J Neurosci Methods (2004) 132:35-43. doi:10.1016/j.jneumeth.2003.08.014

41. McNay EC, Teske JA, Kotz CM, Dunn-Meynell A, Levin BE, McCrimmon RJ, et al. Long-term, intermittent, insulin-induced hypoglycemia produces marked obesity without hyperphagia or insulin resistance: a model for weight gain with intensive insulin therapy. Am J Physiol Endocrinol Metab (2013) 304:E131-8. doi:10.1152/ajpendo.00262.2012

42. Austin E, Deary I. Effects of repeated hypoglycemia on cognitive function: a psychometrically validated reanalysis of the diabetes control and complications trial data. Diabetes Care (1999) 22:1273-7. doi:10.2337/diacare. 22.8.1273

43. Group TDR. Epidemiology of severe hypoglycemia in the diabetes control and complications trial. Am J Med (1991) 90:450-9. doi:10.1016/0002-9343(91) 90605-W

44. The Diabetes Control and Complications Research Group. The effect of intensive treatment of diabetes on the development and progression of long-term complications in insulin-dependent diabetes mellitus. N Engl J Med (1993) 329:977-86.

45. T.D.C.A.C.T.R. Group. Hypoglycemia in the diabetes control and complications trial. Diabetes (1997) 46:271-86. doi:10.2337/diabetes.46.2.271

46. Cornelio AM, Nunes-de-Souza RL. Anxiogenic-like effects of mCPP microinfusions into the amygdala (but not dorsal or ventral hippocampus) in mice exposed to elevated plus-maze. Behav Brain Res (2007) 178:82-9. doi:10.1016/ j.bbr.2006.12.003

47. Degroot A, Treit D. Anxiety is functionally segregated within the septohippocampal system. Brain Res (2004) 1001:60-71. doi:10.1016/j.brainres.2003. 10.065

48. Andersen SL, Teicher MH. Serotonin laterality in amygdala predicts performance in the elevated plus maze in rats. Neuroreport (1999) 10:3497-500. doi:10.1097/00001756-199911260-00006

49. Silveira MC, Sandner G, Graeff FG. Induction of Fos immunoreactivity in the brain by exposure to the elevated plus-maze. Behav Brain Res (1993) 56:115-8. doi:10.1016/0166-4328(93)90028-O

50. McNay EC. The impact of recurrent hypoglycemia on cognitive function in aging. Neurobiol Aging (2005) 26(Suppl 1):76-9. doi:10.1016/j.neurobiolaging. 2005.08.014

51. Cryer PE. Hypoglycemia-associated autonomic failure in diabetes. Am J Physiol (2001) 281:E1115-21.

52. Cryer P. Mechanisms of hypoglycemia-associated autonomic failure and its component syndromes in diabetes. Diabetes (2005) 54:3592-601. doi:10.2337/ diabetes.54.12.3592

53. Roozendaal B, Carmi O, McGaugh JL. Adrenocortical suppression blocks the memory-enhancing effects of amphetamine and epinephrine. Proc Natl Acad Sci U S A (1996) 93:1429-33. doi:10.1073/pnas.93.4.1429 
54. de Quervain DJ, Aerni A, Schelling G, Roozendaal B. Glucocorticoids and the regulation of memory in health and disease. Front Neuroendocrinol (2009) 30:358-70. doi:10.1016/j.yfrne.2009.03.002

55. Quirarte GL, Roozendaal B, McGaugh JL. Glucocorticoid enhancement of memory storage involves noradrenergic activation in the basolateral amygdala. Proc Natl Acad Sci U S A (1997) 94:14048-53. doi:10.1073/pnas.94. 25.14048

56. Roozendaal B, Portillo-Marquez G, McGaugh JL. Basolateral amygdala lesions block glucocorticoid-induced modulation of memory for spatial learning. Behav Neurosci (1996) 110:1074-83. doi:10.1037/0735-7044.110.5. 1074

57. Roozendaal B, Griffith QK, Buranday J, De Quervain DJ, McGaugh JL. The hippocampus mediates glucocorticoid-induced impairment of spatial memory retrieval: dependence on the basolateral amygdala. Proc Natl Acad Sci U S A (2003) 100:1328-33. doi:10.1073/pnas.0337480100

58. Dunn JT, Cranston I, Marsden PK, Amiel SA, Reed LJ. Attenuation of amydgala and frontal cortical responses to low blood glucose concentration in asymptomatic hypoglycemia in type 1 diabetes: a new player in hypoglycemia unawareness? Diabetes (2007) 56:2766-73. doi:10.2337/db07-0666

59. Davis SN, Shavers C, Davis B, Costa F. Prevention of an increase in plasma cortisol during hypoglycemia preserves subsequent counterregulatory responses. $J$ Clin Invest (1997) 100:429-38. doi:10.1172/JCI119550

60. Kale AY, Paranjape SA, Briski KP. I.c.v. administration of the nonsteroidal glucocorticoid receptor antagonist, CP-472555, prevents exacerbated hypoglycemia during repeated insulin administration. Neuroscience (2006) 140:555-65. doi:10.1016/j.neuroscience.2006.02.041

61. Davis SN, Shavers C, Costa F, Mosqueda-Garcia R. Role of cortisol in the pathogenesis of deficient counterregulation after antecedent hypoglycemia in normal humans. J Clin Invest (1996) 98:680-91. doi:10.1172/JCI118839
62. Van Eekelen JA, Jiang W, De Kloet ER, Bohn MC. Distribution of the mineralocorticoid and the glucocorticoid receptor mRNAs in the rat hippocampus. $J$ Neurosci Res (1988) 21:88-94. doi:10.1002/jnr.490210113

63. Reul JM, de Kloet ER. Anatomical resolution of two types of corticosterone receptor sites in rat brain with in vitro autoradiography and computerized image analysis. J Steroid Biochem (1986) 24:269-72. doi:10.1016/0022-4731(86) 90063-4

64. Sapolsky RM. Glucocorticoid toxicity in the hippocampus: reversal by supplementation with brain fuels. J Neurosci (1986) 6:2240-4

65. Lawrence MS, Sapolsky RM. Glucocorticoids accelerate ATP loss following metabolic insults in cultured hippocampal neurons. Brain Res (1994) 646:303-6. doi:10.1016/0006-8993(94)90094-9

66. Virgin CE Jr, Ha TP, Packan DR, Tombaugh GC, Yang SH, Horner HC, et al. Glucocorticoids inhibit glucose transport and glutamate uptake in hippocampal astrocytes: implications for glucocorticoid neurotoxicity. J Neurochem (1991) 57:1422-8. doi:10.1111/j.1471-4159.1991.tb08309.x

67. Roozendaal B. Stress and memory: opposing effects of glucocorticoids on memory consolidation and memory retrieval. Neurobiol Learn Mem (2002) 78:578-95. doi:10.1006/nlme.2002.4080

Conflict of Interest Statement: The author declares that the research was conducted in the absence of any commercial or financial relationships that could be construed as a potential conflict of interest.

Copyright (C) 2015 McNay. This is an open-access article distributed under the terms of the Creative Commons Attribution License (CC BY). The use, distribution or reproduction in other forums is permitted, provided the original author(s) or licensor are credited and that the original publication in this journal is cited, in accordance with accepted academic practice. No use, distribution or reproduction is permitted which does not comply with these terms. 